\title{
Reply to Hutchison and Loomis
}

\author{
Dennis R. Proffitt, Jeanine Stefanucci, Tom Banton, and William Epstein \\ University of Virginia
}

Proffitt, Stefanucci, Banton, and Epstein (2003) reported a set of studies showing that the perceived distance to a target is influenced by the effort required to walk to its location. Hutchison and Loomis (H\&L) reported an experiment that failed to find a significant influence of effort on indices of apparent distance. There were numerous important differences between the design and methods of H\&L's study and those of Proffitt et al. Moreover, there are important theoretical reasons to believe that these differences were responsible for the different results. The theoretical motivation of H\&L's studies was also brought into question.

Keywords: distance perception, spatial perception, energetics, perceived location, intention

Proffit, Stefanucci, Banton y Epstein (2003) proporcionan un conjunto de trabajos en los que se muestra que la distancia a la que se percibe un estímulo-objetivo depende del esfuerzo requerido para caminar hasta él. Hutchison y Loomis (H\&L) presentan un experimento en el que el esfuerzo no produjo efectos significativos en los índices de distancia aparente. Existen numerosas e importantes diferencias entre el diseño y los métodos del estudio de $\mathrm{H} \& \mathrm{~L}$ y los de Proffit et al. Más aún, existen importantes razones teóricas para pensar que tales diferencias causaron las diferencias observadas en los resultados. Se cuestiona la motivación teórica de los estudios de H\&L.

Palabras clave: percepción de la distancia, percepción espacial, consumo energético, localización percibida, finalidad

Correspondence: Dennis Proffitt, Department of Psychology, University of Virginia, P.O. Box 400400, Charlottesville, VA 22904 (USA). Office Phone: 434-924-0655. Fax: 434-982-4750. E-mail : drp@ virginia.edu 
Hutchison and Loomis (H\&L; this issue) claim that they failed to replicate the first experiment in one of our papers (Proffitt, Stefanucci, Banton, \& Epstein, 2003). This claim is questionable on a number or considerations. There were important differences between the design and methods employed by H\&L and us, and there are good reasons to believe that these differences could be responsible for the different results. In addition, we believe that the theoretical motivation underlying H\&L's studies is problematic. H\&L propose that spatial updating is a "pure" measure of perceived egocentric distance. For reasons to be set out later, we are unconvinced. This reply will first detail the methodological differences between $H \& L$ and our study and then provide a brief discussion of our theoretical differences.

\section{Methodological Differences}

In our first experiment, people viewed targets on the ground and made verbal estimates of the distance from themselves to the targets. There were two conditions; one group wore a heavy backpack and the other did not. Those participants who wore the backpack reported targets to be at a greater distance than those who were unencumbered. From these results and those of other studies, we concluded that people's perception of spatial layout is influence by the effort associated with such intended actions as walking (Bhalla \& Proffitt, 1999; Proffitt, in press; Proffitt, Bhalla, Gossweiler, \& Midgett, 1995; Proffitt, Stefanucci, Banton, \& Epstein, 2003; Stefanucci, Proffitt, Banton, \& Epstein, 2005; Witt, Proffitt, \& Epstein, 2004).

H\&L conducted two experiments. The first, like our Experiment 1, employed a between-subjects design, whereas the second used a within-subjects design. Within-subjects designs are inappropriate when the manipulation's anticipated influence on the dependent measure may be obvious to participants, which is certainly the case for the backpack manipulation. If participants are asked to make the same distance judgments either while wearing a backpack or not, then they cannot help but construe the intent of the experiment and conclude that the experimenter anticipates that wearing a backpack will influence their distance judgments. If this were not so, then what possible purpose could motivate the backpack manipulation? It is for this reason that we do not use within-subjects designs when the manipulation is likely to cause participants to infer how the manipulation will influence their experimental task.

As in our experiment, H\&L's Experiment 1 employed a between-subjects design. In H\&L's study, participants estimated distances and also target sizes. One group wore a heavy backpack and the other did not. It is important to note that for both measures, the trends in the data were in the direction that our account predicts; distances and sizes were judged to be larger by those who wore the backpack. These trends, however, were not statistically significant.
There were a number of methodological differences between their study and ours. The following two differences we believe to be the most important.

In our design, there were 4 blocks of trials; within each block, participants saw each of the distances and made a verbal judgment of its extent. The first two blocks served as practice without feedback, which was important for reducing variability; verbal reports become more consistent with practice. The second two blocks gave us two measures for each distance. Thus, our design likely had lower variability due to practice and more statistical power from the repeated measure design. Given that H\&L's data showed trends consistent with our results, these differences could account for the lack of statistical significance.

A second important methodological difference between H\&L's design and ours was that our participants were assessed with only one dependent measure; they provided verbal reports of apparent distance. H\&L's participants' verbal distance estimates were followed by a size judgment, which was then followed by their closing their eyes and walking away from the target. This blind walking was the initial phase of the triangulated-walking measure. Previously, we have shown that effort's influence on perception is conditionalized by the next action that one anticipates performing (Witt et al., 2004). For example, if an experimental manipulation increases the effort associated with walking to a target, then the target will appear farther away if participants anticipate that they will next walk to the target but not if they anticipate, instead, that they will throw a ball to the target's location (Witt et al.). When H\&L's participants judged target distances, it was with the anticipation that they would next perform actions other than walking the extent. H\&L's participants did not anticipate that they would ever walk directly to the target, and for this reason, they may not have been influenced by the effort required to walk this extent.

\section{Theoretical Issues}

H\&L's experiments were designed to show that verbal reports of apparent distance are susceptible to manipulations of walking effort but that triangulated walking is not. Had they obtained this finding, they would have concluded that effort influences post-perceptual processes and not egocentric distance perception, itself. Their rationale is based upon their assertion that the triangulated-walking measure is a "pure" measure of apparent distance, whereas verbal reports are more likely to be influenced by post-perceptual biases. We do not agree that triangulated walking is a pure measure of apparent distance.

In triangulated walking, participants view the target and then are blindfolded. While blindfolded, they walk a distance orthogonal to the initial target direction and then turn and walk to the target. The measure is performed without vision; 
by definition, it is post-perceptual. Only through convoluted argument could it be asserted that a measure obtained without vision is a "purer" measure of visual perception than one in which vision is unfettered.

Not only is triangulated walking post-perceptual, it is not even known whether its performance relies on a perception of distance at all. Triangulated walking requires the spatial-updating of a target's location. Location and distance are not the same. A location is a point; a distance is an extent. A location can be pointed to; a distance cannot. For a target situated on the ground, location can be specified by its angular elevation relative to the horizon or the gravitationally specified vertical. As Sedgwick (1973; 1986) showed, this angle can be used to specify egocentric distance relative to eye-height. For example, if $\alpha$ is the visual angle between the target and the horizon, and the observer's eyeheight is $\mathbf{I}$, then the distance, $\mathbf{d}$, to the object is given by: $\mathbf{d}=\mathbf{I} / \tan \alpha$. It is possible that the processes responsible for the spatial updating of a target's location are based directly upon visual angles - target direction and its angular elevation - without a derivation of distance. H\&L seem to assume an underlying spatial updating mechanism in which perceived distances are represented and combined in an appropriate geometrical representation. Such a mechanism is possible, but there is no evidence that spatial updating mechanisms rely on this sort of process as opposed to ones that rely on visual angles related to location instead.

\section{Conclusion}

There were certainly important methodological differences between H\&L's study and ours that could account for differences between their findings and ours. It is important to again note, however, that their results trended in the same direction as ours. The difference was one of statistical significance; it is not that they found something qualitatively different. More importantly, we think their theoretical stance is underdeveloped and unconvincing. Spatial updating occurs without vision, and thus, its informational basis must be in post-perceptual memory. Moreover, spatial updating is a response to a location, not to a distance, and apparent distance need not be represented by the processes that guide this activity.

\section{References}

Bhalla, M., \& Proffitt, D.R. (1999). Visual-motor recalibration in geographical slant perception. Journal of Experimental Psychology: Human Perception and Performance, 25, 1076-1096.

Hutchison, J.J. \& Loomis, J.M. (this issue). Does energy expenditure affect the perception of egocentric distance? A failure to replicate Experiment 1 of Proffitt, Stefanucci, Banton, and Epstein (2003).

Proffitt, DR. (in press). Embodied perception and the economy of action. Perspectives on Psychological Science.

Proffitt, D.R., Bhalla, M., Gossweiler, R., \& Midgett, J. (1995). Perceiving geographical slant. Psychonomic Bulletin \& Review, 2, 409-428.

Proffitt, D.R., Stefanucci, J., Banton, T., \& Epstein, W. (2003). The role of effort in perceiving distance. Psychological Science, 14, 106-112.

Sedgwick, H. (1973). The visible horizon: A potential source of visual information for the perception of size and distance. Dissertation Abstracts International, 34, 1301-1302B. (University Microfilms No. 73-22530).

Sedgwick, H. (1986). Space perception. In K. R. Boff, L. Kaufman, \& J. P. Thomas (Eds.), Handbook of perception and human performance (Vol. 1, pp 1-57). New York: Wiley.

Stefanucci, J.K., Proffitt, D.R., Banton, T., \& Epstein, W. (2005). Distances appear different on hills. Perception \& Psychophysics, 67, 1052-1060.

Witt, J.K., Proffitt, D.R., \& Epstein, W. (2004). Perceiving distance: A role of effort and intent. Perception, 33, 577-590.

Received March 3, 2006

Review received March 27, 2006

Accepted April 4, 2006 